\title{
Social Studies Preservice Teachers' Views on and Experiences with WebQuest
}

\author{
Fitnat Gürgil ${ }^{1}$, Mertcan Ünal ${ }^{1}$, Bülent Aksoy ${ }^{1}$ \\ ${ }^{1}$ Gazi University, Gazi Faculty of Education, Ankara, Turkey \\ Correspondence: Fitnat Gürgil, Gazi University, Gazi Faculty of Education, Ankara, Turkey.
}

Received: February 14, 2019

Accepted: March 11, 2019

Online Published: March 13, 2019

doi:10.11114/jets.v7i4.4061

URL: https://doi.org/10.11114/jets.v7i4.4061

\begin{abstract}
The current study aims to determine prospective teachers' opinions about WebQuest applications by both introducing them to the WebQuest teaching materials and obtaining their experiences in the WebQuest design process. This study employs phenomenology as a qualitative research approach. The study was conducted in the spring semester of the 2017-2018 academic year with the third year undergraduate students in the social studies education department of a state university in Ankara. Two different data collection tools, a Peer Evaluation Form and an Interview Form, were used. Content analysis was used to analyze the data obtained. According to the findings of the study, social studies preservice teachers think that teacher supervision of Webquest teaching activities is advantageous. Preservice teachers defined the specific principles of WebQuest teaching activities as a weak factor. Additionally, preservice teachers emphasized that WebQuest teaching activities are difficult to implement in environments where Internet and computer facilities are not available. Even though almost half of the participants stated that they wanted to include WebQuest teaching activities in their classes when they started the teaching profession, they expressed about their concerns.
\end{abstract}

Keywords: WebQuest, social studies, preservice teacher, qualitative research

\section{Introduction}

It is important to create information resources from which students can benefit during their learning. Today, the Internet is one of the major resources of accessing information. While all kinds of valuable information is available on the Internet, some of it is missing, biased, or simply useless. It is almost impossible to check and verify every fact and document found on the Internet. Creating a website or sharing information on the Internet is very easy (Açıalın \& Duru, 2005; Akçay \& Şahin, 2012; Kobak-Demir \& Gür, 2018). Different types of data on the Internet may cause learners to get confused about different concepts, which leads students to have difficulties in organizing and verifying the information they receive. The results of the searches performed using search engines may not align with the teaching objectives, and they sometimes lead students to have a look at all the results by preventing them to focus on the subject, and thus wasting time (Faichney, 2002). Biased use of the Internet or websites disturbs families, educators, managers, teachers, and other stakeholders in the field of education (Yoder, 1999). Besides, being faced with unstructured information on the Internet may be a frightening experience for students who are not familiar with searching and doing research, and who do not have the skill to evaluate the information they find. Therefore, students need systematic support to help them gain lifelong learning skills (Peterson, Caverly \& MacDonald, 2003; Faichney, 2002).

Today's youth, who are described by Prensky (2001) as "digital natives," spend most of their time on the Internet (Halat \& Jakubowski, 2001). Although the findings of research on the use of the Internet in education are generally positive, inappropriate Internet content is also a source of concern. WebQuest instructional design developed by Bernie Dodge aims to minimize these concerns. WebQuest is an Internet-based teaching activity that will increase the interest of today's students, and will make it easier for them to conduct research and learn while having fun (Dodge, 1995; Godwin-Jones, 2004; Halat, 2008; Akçay ve Şahin, 2012). Nowadays, due to the advantages of both providing content supported by Internet-based information as well as the ability to control harmful Internet content, the interest in WebQuest teaching activities has been increasing exponentially.

\subsection{What Is WebQuest?}

WebQuest, which is an Internet-based teaching method, was developed by Bernie Dodge at San Diego State University 
in 1995 and developed with the contribution of Tom March who was at the same university. Many definitions of WebQuest have been made in the literature. Dodge (1995), who introduced WebQuest for the first time, defined it as "a teaching approach that organizes Internet-based learning tasks." In 1997, Dodge developed this definition as: "It is a research-focused or research-based activity designed for the best use of a student's time, where students work interactively and acquire some or all of the information from the Internet."

WebQuest teaching activities are divided into two types as long and short term. No matter what kind of teaching, all WebQuest teaching activities must consist of the following six principles. (Dodge, 1995; Dodge, 2001; MacGregor \& Lou, 2005; March, 2000; Sandars, 2005; Yoder, 1999; Halat, 2008): Introduction: The aim of this section, as the first step of WebQuest, is to present a brief overview of WebQuest, followed by a general introduction to the subject and the necessary information for the individuals who will complete the WebQuest, to prepare them for research and inquiry, and to motivate them by drawing their interest to the subject. The most important feature of this section is arousing students' curiosity about WebQuest teaching activities with an interesting scenario or story. Task: This step explains what to do in WebQuest teaching activities and introduces the roles and tasks to be assigned to the learners. The key feature of this section is that the tasks given are meaningful, feasible, interesting, and fun for students. The number of tasks prepared to achieve the target may vary depending on the teacher and subject content. Process: In this step, the learners are told in detail what tools and methods they will use and for how long they will use them during the WebQuest activity, what steps they will take performing the tasks, what their roles involve, and how they should work to fulfill these roles. At this stage, the student is given the information or instructions required to achieve the target. Resources: This step consists of the Internet links to be used by the students in their research which are determined by those preparing the WebQuest. This section should have a list of resources prepared or selected by the teacher to help students complete their tasks. Evaluation: This section explains how the products created by the students will be evaluated at the end of the WebQuest activity. In this section, the work that the student has done, the information he/she has obtained or the point he/she has reached is evaluated by the teacher or researcher. Conclusion: In this section, students are reminded of what they will learn or are expected to learn when they complete the WebQuest.

In the relevant literature, there is some research about WebQuest teaching activities covering various pedagogical levels (Milson \& Downey, 2001; Lipscomb, 2003; Perkins \& McKnight, 2005; Hassanien, 2006; Allan \& Street, 2007; Halat, 2007; Segers \& Verhoeven, 2009; Gülbahar, Madran \& Kalelioğlu, 2010; Kleemans, Segers, Droop \& Wentink, 2011; Akçay \& Şahin, 2012; Çetin \& İnel, 2017; Gürgil, 2018; Ulu \& Ulusoy, 2018). Although the research interest in WebQuest teaching activities has increased in recent years, it still leaves much to be desired. The literature points out that the WebQuest teaching activities in Turkish are particularly limited (Gülbahar et al., 2010; Akçay \& Şahin, 2012). The positive contribution of computer technology to education is frequently emphasized in the literature. Açıalın and Duru (2005) stress that computer-aided education is yet to be optimally practiced in the field of social studies. According to the authors, the inadequate competency of teachers and preservice teachers in computer and Internet technology is an important cause underlying this suboptimal practice. The current study aims to determine prospective teachers' opinions about WebQuest applications by both introducing them to the WebQuest teaching materials and obtaining their experiences in the WebQuest design process. Thus, this study is expected to contribute to the literature and to provide suggestions for future studies.

\section{Method}

This study employs phenomenology as a qualitative research approach. According to Ersoy (2017), phenomenological research is based on personal perceptions and experiences of individuals. The social studies preservice teachers participating in the study were given information about WebQuest and then they were asked to create a WebQuest design themselves. In this way, their opinions and evaluations about WebQuest applications were obtained after their direct involvement and experience with WebQuest.

\subsection{Participants}

The study was conducted in the spring semester of the 2017-2018 academic year with the third year undergraduate students in the social studies education department of a state university in Ankara. It was carried out in two phases. A total of 75 pre-service teachers ( 35 male and 40 female) participated in the first phase of the study. In the second phase, a total of 25 pre-service teachers, 11 of whom were male and 14 were female, experienced WebQuest teaching activities as suggested by Polkinghorne (1989, cited in Creswell, 2013). In the first phase of the study, the participants prepared some WebQuest teaching activities related to the social studies lesson units. All these activity designs were evaluated by the other preservice teachers participating in the study. In the second phase of the study, semi-structured interviews were conducted with 25 pre-service teachers. These participants were selected among the first phase pre-service teachers.

\subsection{Procedure}

The social studies preservice teachers participating in the study were given a 4-week WebQuest training. In the first 
three weeks of this training, the WebQuest program was introduced and the participants were asked to apply their knowledge of the program through some samples. In the fourth week, the most common problems experienced by the participants were paid particular attention to make sure they are resolved. The participants were asked to prepare WebQuest teaching activities on any unit of the social studies course, either as a group or individually. For ten weeks, after the completion of the training process, the participants presented the WebQuest designs that they had designed individually or as a group.

\subsection{Data Collection Tools}

Two different data collection tools, a Peer Evaluation Form and an Interview Form, were used.

Peer Evaluation Form: A form was prepared by the researchers in order to enable prospective teachers to evaluate their peers. The prepared form consists of two parts. The first part includes information about the evaluated group/individual and the questions about the preservice teacher carrying out the evaluation. In the second part of the draft form, the preservice teachers were asked four questions. After expert opinions were consulted, two questions were merged and one question was removed from the form, resulting in the final version of the form that included two questions. This form was handed out to the participants before each presentation. The following questions were asked to the participants in the Peer Evaluation Form:

1. What are your favorite parts of the WebQuest unit that your friends have prepared, and what are the parts that you would definitely create if you prepared this work? Can you explain?

2. What are your least favorite parts of the WebQuest unit that your friends have prepared, and what are the parts that you would definitely not create if you prepared this work? Can you explain?

Interview Form: For the questions that were planned to be included in the interview form, firstly, a pool of questions was created in line with the purpose of the study. Then, two faculty members specialized in qualitative research and two faculty members specialized in computer and instructional technology education were consulted. In line with the expert opinions, a question was added to the interview form and thus the form was finalized. After the completion of the WebQuest presentations, preservice teachers were interviewed. The interview questions asked to the participants are as follows:

1. Considering the WebQuest you have prepared, what do you think are the strengths of WebQuest teaching activities?

2. Considering the WebQuest you have prepared, what do you think are the weaknesses of WebQuest teaching activities?

3. What difficulties did you have in the process of preparing WebQuest teaching activities?

4. Do you plan to use WebQuest teaching activities in your future teaching? Why?

5. How would you briefly describe the feeling you experienced in the process of preparing WebQuest teaching activities?

\subsection{Data Analysis}

Content analysis was used to analyze the data obtained. The interviews were completed in the researchers' offices $(n=3)$ and in the available classrooms $(\mathrm{n}=22)$ in the faculty of education building. Each interview was recorded with a sound recorder. The interviews lasted 20-25 minutes on average. The interview data were transferred to a computer first. All of the interviews were read thoroughly three times. In each reading, the interview data were coded on the margins of the pages. The similarities in the statements of the participants were merged under some themes. The opinions of prospective teachers are presented and supported with direct quotations in the findings section. Similar procedures were also performed for the Peer Review Forms. Firstly, the codes were formed for the Peer Evaluation Forms. Then, similar expressions were collected under a theme and presented in the findings section.

Two researchers analyzed all the data separately. To determine the reliability of the study, the [Reliability = Consensus / (Consensus + Dissidence)] formula developed by Miles and Huberman (1994) was used. The inter-coder reliability rate between the coders for the interview data was found to be $88 \%$. The first coder analyzed all the Peer Evaluation forms. Since the number of the Peer Evaluation forms was too high (over 2000), the second coder coded only $20 \%$ of them, which were randomly-selected. The inter-coder coherence rate between the coders for the same forms encoded by two different coders was also examined, which was found to be $95 \%$. Some of the participant opinions are presented in the findings section with direct quotations. Each participant is assigned a code to conceal their identity (e.g. PS1F). Regarding the PS1F code, "PS" indicates a Preservice Teacher; " 1 " indicates the participant's interview order, and "F" was used to express that the gender of the participant was female. 


\section{Results}

In this section focusing on social studies preservice teachers' views about WebQuest implementation, first, the elicited opinions will be presented, and then the peer evaluation results will be discussed.

\subsection{Social Studies Preservice Teachers' Opinions about WebQuest Implementation}

In the interviews held with the preservice teachers, the participants were firstly asked the question of "What are the strengths of WebQuest when you think about the WebQuest you've prepared?" As the strengths of WebQuest, the most important factor stressed by the preservice teachers $(n=18)$ is "the control of the resources by teachers". According to the participants, through such control, the students not only will be kept away from the inappropriate Internet environment but, also the digital learning environments required by the age will be used. PS10M expressed her opinion on this subject as: "In my opinion, WebQuest's most important strength that is distinctive from the materials used in other computer environments is that the teacher presents the information after filtering it. That's very nice. In this way, students can be protected from harmful content on the Internet and learning occurs in a modern educational environment (...)." For the same question, some preservice teachers stressed that WebQuest allows learning outside the school. The participants stated that the use of WebQuest is quite advantageous, especially for the completion of the subjects that could not be covered in the class or the materials that cannot be brought into the classroom environment. Participant PS9F made the following explanation: "It is difficult to bring every material into the school environment. I think WebQuest helps with that. For example, the class time may not be enough to cover the unit titled as 'Turks on the Silk Road' (a very long unit). Students can make up for the missing sections with the WebQuest, or the entire unit can be completed with out-of-school WebQuest teaching activities."

Some pre-service teachers emphasized that the WebQuest practice was fun while some others stressed that WebQuest included tasks that encouraged students to become more active. PS12M stated that "I think WebQuest combines fun and learning. This distinguishes it from the other approaches (...)". Pre-service teacher PS11F emphasized that the students were more active thanks to their assigned tasks: "In the courses taught with WebQuest, students perform their tasks in a fun way. Very different from the regular classroom environment. They watch a video, but, as they watch, they try to find the answer to the questions they are asked. Students become more and more active by using the continuous research and inquiry skills." PS25M highlighted reaching out to a higher number of people as a strength of WebQuest: "In a normal classroom environment, only your students can benefit from the course, while in the lessons prepared with WebQuest groups of students you do not know at all can also benefit from your course (...).” PS15M emphasized WebQuest's enabling equal opportunity in education: "WebQuest is more important for children who lack many facilities. It is normal that private school students can visit museums, but, thanks to WebQuest, through tasks assigned in virtual museums peasant children can also benefit from such opportunities, which will ensure equal opportunities in education. Even in schools without teachers, some gaps can be closed with WebQuest. Thus, the gap stemming from socioeconomic status would be smaller. Good education can spread everywhere (...)."

Regarding the same question, some preservice teachers thought that WebQuest was strong because it supported individual learning. Participant PS24F explains this point by saying that "With WebQuest, students can study the course content as many times as they want, so it is very useful in this respect. In addition, students do not learn the same way at the same speed. I think WebQuest is useful to learners with different learning styles. Students can go back and revise the content which they are struggling with. Some students could be learning faster on their own, and the lessons taught in the classroom might be slowing them down. Otherwise, because they cannot catch up with the instruction speed in the classroom environment, they might be missing some important points. All these are resolved thanks to WebQuest." Some participants underscored the ease of use as a strength of WebQuest. For example, participant PS17M says that "I don't think you need extra computer knowledge. Every student who knows the basic usage of the computer can use it easily. This is an important advantage of using WebQuest." For the same question, two participants pointed out that WebQuest materials could be updated more quickly and easily than printed materials such as textbooks, as exemplified by PS9F: "I think that this program goes beyond the limits of textbooks and teaching programs. So in the digital age, curricula and books cannot be updated as frequently as they should be. However, as in such programs, the teacher can immediately add any updates to the teaching environment."

As the second question, the participants were asked the question "Considering the WebQuest you have prepared, what do you think are the weaknesses of WebQuest teaching activities?" Most of the preservice teachers who participated in the interview pointed at WebQuest's failure to support a flexible design process as a weakness. Participant PS16M reported: "Too bad it doesn't go beyond certain structures. Everything is designed in steps. I wish I could create a more flexible design. That (inflexibility) bored me. I think students will get bored as well." Concerning the same question, some participants stated that there would be problems in WebQuest use in environments where there is no Internet and computer facilities. Participant PS11F drew attention to the need for Internet and computer infrastructure support: 
"There are so many schools where there is no Internet or computers. Everything is planned for the cities. It is not suitable for use in village schools where there is no Internet (...) There is no way you can apply this with the rural children. There are no computer labs at school, and their homes do not even have a computer, let alone the Internet!" As a weakness of WebQuest, some preservice teachers stated that the content creation for the course took too much effort and time. Participant PS3M stated the following: "Preparing WebQuest is a long and laborious job. Especially if the gains in the unit you choose are too many, it gets harder. On top of that, if you cannot find the proper sources, you will have to do everything yourself (...)." PS12M pointed at the difficulties in creating subject-appropriate course material: "Although I did a lot of research while preparing my unit, I had great difficulty in finding the suitable content. Even if there seems to be many resources available, they either do not contain reliable information or are above or below the student level. Instructional content is important in WebQuest designs, but hard to find on every subject."

Some participants emphasized that WebQuest practices weaken face-to-face communication with students. Participant PS7F explains this point by: "Social studies course has a high level of human focus. The basis of face-to-face communication of people is given in this course. I don't think it is right to teach children the rules of communication such as listening properly, being respectful, and making requests and then taking them into a virtual world. Children already spend too much time in the virtual world. Let them do their lessons by touching, talking, and feeling within humane relations (...)." As a weakness of WebQuest practices, Participant PS20M reported the difficulty in students' supervision: "How much control can you have on students in the virtual world? Even if we carefully examine the links we provide, the student can somehow come across some problematic texts, pictures, videos and so on. Although there are similar limitations in all Internet-related educational tools, (...) the child can tell the teacher that he / she is studying and can easily shift focus on other harmful content."

As another question, the prospective teachers were asked "What difficulties did you have in the process of preparing WebQuest?" The difficulties reported by the pre-service teachers are classified into seven different themes. The difficulty that was paid the strongest attention by the participants is the fact that WebQuest design requires following certain principles, which was quite challenging for them. Participant PS3M explained this point as follows: "The program is not like the other programs we used before. Everything needs to be placed in a template, which prevents creativity. We couldn't apply the design we had on our minds because we had to meet a wide range of criteria first." Similarly, Participant PS4F highlighted the rigidity of the WebQuest design: "The interface of the site was not user-friendly. That is why we could not do what we had planned to do and failed to perform at our best. You feel limited because WebQuest requires that you have to have this and that on this many pages." Most of the participants stated that they had difficulty adding the necessary links during the WebQuest design. Participant PS10M explained this as follows: "(...) I had difficulty placing the video, content and photos. Copy-paste does not work. All this makes you tired and makes you lose even more time." Another difficulty reported by more than half of the participants is that this design is more labor- and time- intensive than other digital designs. Participant PS25M reported "I spent a lot of time and effort trying to make sure everything is by the book. It took more time than other digital education tools. (...)." 11 of the preservice teachers stated that they had difficulty in preparing appropriate content. For example, Participant PS5M reported her experience as follows: "I had a hard time finding reliable sources. Resources must be reliable; otherwise, you have to prepare them. It was incredibly difficult. Also, the links you use may change even in a few hours or they may become inaccessible. Unfortunately, that's what happened to me. (...)."

One of the two participants who stated that they had a quota problem during the WebQuest preparations is PS18F: "Because our scenario was too long, or rather our unit had a very wide coverage, the parts determined on the interface were not enough. But, unaware of that, we continued to work, work, work! But then we saw that most of them were not recorded. Then we asked about it to our teacher. As it turns out, our web program had a limit! And we have had surpassed it (...)." Two participants stated that they had problems due to limited Internet services. One of these participants, PS21M, reported the following: "My biggest problem was that I didn't have Internet access at home. The computer labs of the university were not adequate. I had a hard time finding a place. When I found the Internet, it was either too slow or the computers I used were malfunctioning." As a difficulty in WebQuest design, one participant pointed at not having adequate computer competence. Participant PS20M said "I don't know about the computers much. That has added a lot more to my workload (...)."

The preservice teachers were further asked, "Do you plan to use WebQuest teaching activities in the future? Why?" 14 of the 25 preservice teachers who participated in the semi-structured interviews stated that they plan to include WebQuest designs in their classes when they start teaching as in-service teachers. Six of these preservice teachers emphasized that the WebQuest resources are reliable. For example, PS1F reported "I'm thinking of using it in my lessons because each stage is being controlled and prepared by the teacher. So, it's free of false information and harmful effects." As one of the three preservice teachers who think that the lessons will be more interesting with WebQuest, PS5M reported the following: "I will use it because I think students will be interested." PS13F, who is one of the two 
participants who stated that they are considering using WebQuest applications as a homework tool, reported the following: "I plan to. In particular, I think I should use it as a homework tool (...)." PS23F, who says her students will use the WebQuest design in her classes in order to catch up with the technology age, states the following: "Of course I am planning to use it because the age we are going to teach in is the age of technology. My students should not fall behind the age." PS8F, who states that she will use WebQuest applications for the purpose of completing the unfinished lessons, thinks the following: "Yes, I plan to. Good in terms of continuing the lessons. At home, students will continue to build on what they have learned in the classroom. Thus, they will be able to make up for the parts of the courses they are missing." PS21M emphasized the free use of WebQuest applications: "Why shouldn't I (use it)? It is a free application; of course I will use it. After all, we're not paying for it!"

11 of the 25 preservice teachers who designed WebQuest stated that they did not want to include WebQuest designs in their future classes. The most important reason why the participants do not want to include WebQuest designs in their classes is that they think that the IT facilities of their future schools will not be adequate to support such a design. This is exemplified by PS22F by: "No. Because our place of employment will usually be the most rural areas of Turkey. This will not change for many years. I think the schools in Turkey have hardware problems. I do not think I could even if I wanted to. Maybe it will be possible in my 10th year in the profession. But then there will be so many different software programs in the market." An examination of the rationale for three prospective teachers who do not plan to use WebQuest reveals that the dangers in the virtual environment are the primary concern. In PS15M's words: "No, because even though we inspect and control the content, the student can access inappropriate content even when watching a video. It is very difficult for a teacher to prepare a fully original WebQuest. Therefore, he or she has to take contents from various sources. In addition, while we may think that the student is working on a classroom task, we cannot be sure that he or she is not actually playing an online game. I think the Internet dangers are not completely addressed by this program. So I don't intend to use it." Two participants, who stated that they did not intend to include WebQuest in their lessons, cited the WebQuest design as requiring too much labor and time. One of these participants, PS17M's views are as follows: "I do not think so. Because it is so hard. I do not think we will have that much time when we are a(n inservice) teacher. It took us several weeks to prepare a unit as a group. I don't think we will have that much effort and time when we are teachers." Another preservice teachers (PS25M) who participated in the interviews also stated that she did not intend to use the WebQuest designs, citing the limited benefit they offer: "I never plan to (use them). This process has been an experience for me, that is all. I have learned what WebQuest is. But, I don't think WebQuest is much useful-friendly. Instead, there are much more user-friendly platforms. (...) I'll use them.” A participant (PS7F) who reported that she did not plan to use WebQuest designs in her classes expressed her intention to teach face-to-face in the classroom: "No, my teaching will be based on human relationships. Today's children are always at the computer anyway, so I think they should stay away from the computer during the courses."

Finally, the participants were asked the question of "How do you briefly explain the feeling you experienced in the process of WebQuest preparation? In the interviews, five of the pre-service teachers explained their emotions with the word 'happiness.' As PS19F reported: "I was simply happy. The happiness of being finished!" As for the dominant feeling, four participants underlined 'Excitement', as exemplified by PS4F: "I liked it. Usually excitement was the most dominant feeling I had (...)". Likewise, four participants highlighted the 'Self-confidence' theme. PS23F explained her feelings as follows: "Now I feel like a triumphant commander. There is a peace of mind from accomplishment and an explosion of self-confidence." Underscoring the labor- and time intensive nature of the research process, four of the participants summed up the WebQuest design process by the word 'Tiredness', as in PS21M's words: "I've worked hard every second of it. I cannot believe it is over. I feel very, very tired when I think about it. I do not think I would do it again. It was so tiring (...)." Three participants explained their emotional status with the word 'Boring', as reported by PS22F: "Boring. I was bored while doing it. I cannot even imagine what the students would feel." The same number of participants $(\mathrm{n}=3)$ explained their feelings by the theme of 'Anxiety'. Ö PS17M reported the following: "There was a constant anxiety in the construction process. I had constant stress (...). The word anxiety defines my feelings the best." PS20M reported that the feeling of regret outweighs all others: "In one word 'regret'. Because I could have done better. My biggest mistake was not choosing an easy unit for the WebQuest. That's why I regret it." A prospective teacher who designed a social studies unit with WebQuest explained the emotion related to the process with the theme of "Mixed Feelings'. PS24F reported the following: "I don't know what I feel! I am happy it is over but, I am still sorry. I am glad I succeeded at it, but, I could have done better. That's why I'm sorry."

\subsection{The Most Important Factors Paid Attention by Preservice Social Studies Teachers in Their WebQuest Design}

At the beginning of the research process, preservice teachers were told that they could prepare the WebQuest teaching activities either individually or as a group. 75 preservice teachers participated in the study, and 35 different WebQuest designs were created. During the presentation of each design, by using the Peer Evaluation Form, the participants evaluated the WebQuest teaching activities prepared by their peers. 
An analysis of the completed Peer Review Forms reveals that the first five elements highlighted in the highest rated WebQuest designs are as follows: Well-prepared scenario $(f=347)$, use of reliable sources $(f=344)$, development of higher-order thinking skills $(f=317)$, achievement of all the objectives $(f=287)$ and appropriateness to the student level ( $f=209$ ). The Peer Review Forms also indicate that especially the fictional texts prepared in a way to keep the middle school students' interest and curiosity alive received higher scores. It is also important that WebQuest designs prepared for preservice teachers consist of reliable sources. The reliable source criterion for prospective teachers is that the designer either prepares the whole content or bases it on official resources. Again, according to the participants, another important factor is that the tasks given to the students are designed to develop high-level thinking skills such as critical thinking, problem solving and creative thinking. Achievement of all the objectives of a unit is also one of the elements that should be included in a good WebQuest design. Preparing the WebQuest designs according to the student level is another important criterion stressed by the participants.

The first five elements that preservice teachers criticize most in the Peer Review Forms are as follows: Giving links without purpose $(f=369)$, overuse of the videos $(f=332)$, being above student level $(f=318)$, typographical errors $(f=$ 258 ), and guiding students inadequately ( $\mathrm{f}=225)$. One of the most important shortcomings is the inclusion of resources into WebQuest designs without any apparent specific purpose. The majority of the participants criticized their peers who overused entertaining videos in an attempt to make their WebQuest fun. Some participants also criticized that the WebQuests for the lower classes was above the student level. The language used by preservice teachers emerges as another very important criterion. The use of improper font sizes and grammar was heavily criticized in the Peer Review Forms. According to the participants, all the visual or auditory data included in the design should serve a purpose and guide the students. Therefore, the data used without any purposes were criticized intensively by these prospective teachers.

In analyzing the Peer Evaluation Forms, a particular attention needs to be given to the games and videos because preservice teachers' use of video in WebQuest designs is an important plus. Videos bring fun while increasing student interest in the lesson. However, using these videos aimlessly or using multiple videos for similar purposes was observed as an important deficiency and was heavily criticized. The preservice teachers criticized not only the content of the videos but, also their technical qualities in the Peer Review Forms. For example, videos' low sound quality or failing to open was an important source of criticism. In the same way, the games used by the pre-service teachers were liked as interest and curiosity elements for WebQuest designs, while the games that were overused or used without a clear reason were criticized. According to pre-service teachers, games and videos in WebQuest design should be used in accordance with the students' levels for specific purposes. In addition, each game and video should be closely related to the subject of the course and support the development of the student.

\section{Conclusion and Discussion}

This study aims to determine the opinions of prospective social studies teachers about WebQuest practices based on their WebQuest experiences. It was found that, as a result of their experiences in the process, the preservice teachers highlight different features as the positive aspects of teaching with WebQuest. Teacher supervision of the resources used in WebQuest teaching activities emerged as the factor that was emphasized most vigorously by the preservice teachers. Milson and Downey (2001) state that the WebQuest teaching activities minimize the negative effects of the Internet. Warning that there are many controversial web pages on the Internet, Perkins and McKnight (2005) stress that WebQuest teaching activities can be completed without any need for search engines. For this reason, access to inappropriate web pages is also minimized in WebQuest teaching activities.

Another strength of WebQuest teaching activities mentioned by the participants is that WebQuest teaching activities help students learn by having fun. Previous studies in the literature confirm that WebQuest teaching activities increase student motivation in the classroom and contribute to their learning by helping them have fun (Lipscomb, 2003; Perkins \& McKnight, 2005; Hassanien, 2006; Halat, 2008; Gülbahar et. al, 2010; Ulu \& Ulusoy, 2018). As such, this finding is consistent with the literature. Another feature highlighted by the prospective teachers about WebQuest teaching activities is that students are more active in the lesson thanks to the tasks given to them. Other studies in the literature also indicate that students are more active in WebQuest teaching activities (Halat \& Jakubowski, 2001; Halat, 2008; Akçay \& Şahin, 2012). In this sense, our research results are supported by the literature.

Another strength highlighted by the participants about WebQuest teaching activities is that WebQuest teaching activities contribute to the development of students' high-level thinking skills. This finding is consistent with other research results in the literature (Milson \& Downey, 2001; Zheng, Stucky, McAlack, Menchana \& Stoddart, 2005; Aç1kalın \& Duru, 2005; Lacina, 2007; Halat, 2008; Polly \& Ausband, 2009; Segers \& \& Verhoeven, 2009; Gülbahar et al, 2010; Akçay \& Şahin, 2012; Ulu \& Ulusoy, 2018). It was also found that some of the prospective teachers stressed the low cost of WebQuest teaching activities. Similarly, the study conducted by Gülbahar et al., (2010) found that preservice 
teachers emphasized the low cost of WebQuest teaching activities as an advantage.

The study also determined that the pre-service teachers defined the principles of WebQuest design (introduction, task, evaluation, etc.) as a weakness that limited their creativity. However, Gülbahar et al., (2010) determined that preservice teachers found the principles of WebQuest designs very useful. This difference in the opinions of prospective teachers can be explained by the duration of the WebQuest experience. The research carried out by Gülbahar et al., (2010) continued for one year in two different courses, and thus the preservice teachers involved in their study became more familiar with the WebQuest teaching activities. The present study, on the other hand, was part of a course on WebQuest teaching activities and continued for 14 weeks. The WebQuest principles criticized by the participants actually provide teachers with a framework in their course content planning, ensuring a more systematic instructional design. Therefore, the social studies preservice teachers seem to need more experience to change their perception of these principles.

Another weakness pointed out about WebQuest is the difficulty of using it in environments without Internet or computer facilities. The difficulty of implementing WebQuest in the absence of computer facilities and Internet access was highlighted by previous studies (Halat \& Jakubowski, 2001; Perkins \& McKnight, 2005; Akçay \& Şahin, 2012). In the literature, besides the lack of fast and reliable Internet (Halat \& Jakubowski, 2001; Halat, 2008), faulty or dead links (Perkins \& McKnight, 2005) are also stated as some common problems. Related to this problem, the statement made by one of the participants that "(...) the links you use may change even after a few hours or they may not be accessible. This is what happened to me, unfortunately (...)." is supported by the literature.

One of the most prominent weaknesses of WebQuest teaching activities highlighted by the participants is that WebQuest teaching activities require much time and effort. This finding obtained in the current study was found to be consistent with different studies in the literature. Previous studies confirm that both preparing and implementing WebQuest teaching activities are difficult and time consuming (Halat \& Jakubowski, 2001; Perkins \& McKnight, 2005; Hassanien, 2006; Halat, 2008; Akçay \& Şahin, 2012).

The fact that it was difficult for preservice teachers to find proper materials and resources for every subject during the design process was also expressed as a weakness of WebQuest teaching activities. Previous studies also discuss the preparation of appropriate content related to WebQuest teaching activities. Akçay and Şahin (2012) draw attention to the difficulty of finding reliable sources for WebQuest especially for the lower grade levels in Turkey, and that content to be used for WebQuest teaching activities available in Turkish is very limited. Gülbahar et al., (2010) also emphasize the inadequacy of WebQuest teaching activities in Turkish. It has also been shown by other research in the literature that it is difficult and laborious to prepare appropriate content in WebQuest (Halat \& Jakubowski, 2001; Perkins \& McKnight, 2005). Lipscomb (2003) and Lacina (2007) offer a variety of suggestions to teachers on how to prepare appropriate content in WebQuest. Lipscomb (2003) says that teachers can use the available WebQuests as they are or with minor modifications. Lipscomb (2003), Perkins \& McKnight (2005) and Lacina (2007) suggest that teachers first analyze the available WebQuests. Lipscomb (2003) says that some WebQuests may have problems in the links they have, even though they might be appropriate in terms of appearance. If the number of resources used in the WebQuest is low, the students may feel forced to check search engines, but if there are too many resources, the students may get bored and distracted. Lipscomb (2003) therefore recommends that teachers prefer WebQuests with adequate content. Lipscomb (2003), Perkins \& McKnight (2005) and Lacina (2007) underline the need for the teacher to carefully review the information presented in the WebQuest. Lipscomb (2003) also recommends the examination of the availability and usability of the computers in the classroom. In addition, in order to avoid problems related to computer or Internet access in the classroom environment, it is also helpful to have some books, journals and textbooks that are relevant to the subject to be taught.

We also found that some participants exhibited negative attitudes towards WebQuest teaching activities due to their restriction of face-to-face communication. Hassanien (2006) states that technology-based education restricts human communication. Ulu and Ulusoy (2018) assert that reading from the screen is disadvantageous for students' ocular health. In WebQuest designs, spending too much time on the computer screen may harm students' eye health. Our study also found that although the participants evaluated the communicative aspects of WebQuest, they made no evaluations regarding health.

$56 \%$ of the prospective teachers stated that they want to include WebQuest practices in their classes when they start teaching. The reasons given for the prospective teachers' intention to use WebQuest teaching activities are as follows: WebQuest practices are free of harmful and biased information, are interesting for students, help complete the missing courses, and can be used as homework tools. In the study conducted by Gülbahar et al. (2010), preservice teachers reported that they want to use WebQuest teaching activities in their courses due to the reasons such as encouraging students to study, increasing their interest in the lesson and improving their computer literacy. Their study also found that prospective teachers plan to include WebQuest in their courses as homework assignments. In a similar vein, Lacina 
(2007), and Ulu \& Ulusoy (2018) suggest that WebQuest can be used for homework purposes. Therefore, this finding is supported by the literature.

Previous research results indicate that teachers have low proficiency in using computers (Açıkalın \& Duru, 2005; Segers \& Verhoeven, 2009; Polly \& Ausband, 2009; Ulu \& Ulusoy, 2018). Perkins \& McKnight (2005) discuss teacher proficiency in the context of WebQuest teaching material. The authors state that very few teachers have adequate knowledge in designing a high-quality WebQuest. According to Perkins and McKnight (2005), teachers should be informed about WebQuest, which is an excellent training tool when used properly. Polly and Ausband (2009) state that teachers need more experience and more time to grasp the logic of WebQuest and to prepare high-quality WebQuests. Hassanien (2006) states that students need more time to complete their WebQuest tasks. Based on the results of the present studies, it can be said that both the preparation and implementation of WebQuest teaching activities take more time than other teaching activities.

We also found that the criterion that preservice teachers gave the most attention in their peer evaluation forms was well-designed fictional texts (scenarios). According to the participants, well-prepared scenarios attract students to WebQuest teaching activities, resulting in better learning. Halat (2008) points out that the scenario or topics in WebQuest teaching activities can be boring when students do not like it or find the assigned tasks too difficult. Thus, to prevent this problem, it is vital that WebQuest activities should be selected according to the target students' ages and interests. Hassanien (2006) states that the overall results of WebQuest teaching activities are very positive but, that it is not that positive for students with low computer literacy. In this sense, determining students' computer literacy status is one of the key points for these teaching activities. Teachers are advised to determine their learners' computer literacy status before applying WebQuest activities. Hassanien (2006) reports that well-planned computer-aided education increases the learning outcomes by 1/5. Zheng et al., (2005) assert that WebQuest teaching activities can be used at all stages of education, from preschool to higher education. However, the authors also underline that WebQuest teaching activities are not suitable for all subjects.

As a result of the findings of the current study, the following suggestions can be made:

- Undoubtedly, the widespread use of WebQuest-style computer and Internet-supported teaching materials depends on teachers' correct understanding and application of such materials. For this reason, teachers' shortcomings in using computer- and Internet-supported teaching materials can be addressed through seminars.

- WebQuest activity samples can be collected in specific country-based data-bases and made available to teachers. Especially for countries like Turkey, which are not at the desirable level in using WebQuest teaching activities, such practices can be expected to have positive results. Teachers can initially make various changes to the existing WebQuests, and can later prepare their own WebQuest teaching activities. In this way, both the time problem can be resolved, and WebQuest designs with higher quality can be obtained.

- The effectiveness of WebQuest teaching activities can be investigated in future studies. Future research may also use course observations and alternative assessment methods. The relevant research literature frequently emphasizes that WebQuest teaching activities develop high-level thinking skills. In the future research, the effects of WebQuest teaching activities on students' high-level thinking skills can also be explored.

- The findings obtained in this study indicate that social studies preservice teachers need to have more experience with and spend longer time on WebQuest teaching activities. Preservice teachers' familiarity with WebQuest teaching activities can be strengthened during their undergraduate training by having them apply WebQuest in various courses so that they can gain an accurate understanding of WebQuest and use it properly in their professional careers.

\section{References}

Açıkalın, M., \& Duru, E. (2005). The use of computer technologies in the social studies classroom. The Turkish Online Journal of Educational Technology - TOJET, 4(2), 18-26.

Akçay, A., \& Şahin, A. (2012). Effect of WebQuest learning method on academic success and attitude in Turkish lessons. Journal of Educational Sciences Research, 2(2), 33-45.

Allan, J., \& Street, M. (2007). The quest for deeper learning: an investigation into the impact of a knowledge-pooling WebQuest in primary initial teacher training. British Journal of Educational Technology, 38(6), 1102-1112, https://doi.org/10.1111/j.1467-8535.2007.00697.x

Çetin, T., \& İnel, Y. (2017). Webquest applications in teaching geography. Adem Sezer (Editor), Geography Teaching Technologies and Material Design In (p.243-254) Ankara: Pegem Yayıncılık

Creswell, J. (2013). Qualitative inquiry and research design: Choosing among five traditions. Thousand Oaks, CA: 
Sage Publications.

Dodge, B. (1995). WebQuests: A technique for internet-based learning. Distance educator, 1(2), 10-13.

Dodge, B. (1997). Homepage. Some thoughts about WebQuest. Retrieved September 23, 2018 from the World Wide Web: http://webquest.org/sdsu/about_webquests.html

Dodge, B. (2001). FOCUS: Five rules for writing a great WebQuest. Learning and Leading with Technology, 28(8), 6-9.

Ersoy, A. F. (2017). Phenomenology. Ahmet Saban, Ali Ersoy (Editors), Qualitative Research Patterns in Education In (p.81-138) Ankara: Anı Yayınc1lı.

Faichney, G. (2002). WebQuest: A strategy for teaching sose online, ETHOS, 6(10), 145-168.

Godwin-Jones, R. (2004). Language in action: From webquests to virtual realities. Language Learning \& Technology, 8(3), 9-14.

Gülbahar, Y., Madran, R. O., \& Kalelioğlu, F. (2010). Development and evaluation of an interactive WebQuest environment: "Web Macerasi”. Educational Technology \& Society, 13(3), 139-150.

Gürgil, F. (2018). The effect of authentic learning approach in social studies teaching on the academic success. Universal Journal of Educational Research, 6(10), 2061-2068. https://doi.org/10.13189/ujer.2018.061002

Halat, E. (2007). Views of pre-service elementary teachers on the use of webquest in mathematics teaching. Elementary Education Online, 6(2). 264-283.

Halat, E. (2008). A good teaching technique: WebQuests. The Clearing House: A Journal of Educational Strategies, Issues and Ideas, 81(3), 109-112. https://doi.org/10.3200/TCHS.81.3.109-112

Halat, E., \& Jakubowski, E. (2001). Teaching geometry using WebQuest. Proceedings of the nineteenth International Conference on Technology and Education, Tallahassee, Florida.

Hassanien, A. (2006). An evaluation of the Webquest as a computer-based learning tool. Research in Post-Compulsory Education, 11(2), 235-250. https://doi.org/10.1080/13596740600769230

Kleemans, T., Segers, E., Droop, M., \& Wentink, H. (2011). WebQuests in special primary education: Learning in a web-based environment. British Journal of Educational Technology, 42(5), 801-810. https://doi.org/10.1111/j.1467-8535.2010.01099.x

Kobak-Demir, M., \& Gür, H. (2018). The predictor variables of qualification for technologic-supported instructional materials WebQuests. J. BAUN Inst. Sci. Technol., 20(1), 156-173.

Lacina, J. (2007). Technology in the classroom: Inquiry-based learning and technology: Designing and exploring WebQuests. Childhood Education, 83(4), 251-252. https://doi.org/10.1080/00094056.2007.10522926

Lipscomb, G. (2003). I guess it was pretty fun: Using WebQuests in the middle school classroom. The Clearing House: A Journal of Educational Strategies, Issues and Ideas, 76(3), 152-155. https://doi.org/10.1080/00098650309601993

MacGregor, S. K., \& Lou, Y. (2005). Web-based learning: How task scaffolding and web site design support knowledge acquisition. Journal of Research on Technology in Education, 37(2), 161-175. https://doi.org/10.1080/15391523.2004.10782431

March, T. (2000). "WebQuests 101": Tips on Choosing and Assessing WebQuests. Multimedia Schools, 7(5), 55-58.

Miles, M. B., \& Huberman, A. M. (1994). Qualitative data analysis: An expanded sourcebook. Thousand Oaks, CA: SAGE.

Milson, A. J., \& Downey, P. (2001). Webquest: using internet resources for cooperative inquiry. Social Education, 65(3), 144-146.

Perkins, R., \& McKnight, M. L. (2005). Teachers' attitudes toward WebQuests as a method of teaching. Computers in the Schools: Interdisciplinary Journal of Practice, Theory, and Applied Research, 22, 123-133. https://doi.org/10.1300/J025v22n01_11

Peterson, C., Caverly, D. C., \& MacDonald, L. (2003). Techtalk: Developing academic literacy through WebQuests. Journal of Developmental Education, 26(3), 38-39.

Polly, D., \& Ausband, L. (2009). Developing higher-order thinking skills through WebQuests. Journal of Computing in Teacher Education, 26(1), 29-34.

Prensky, M. (2001). Digital natives, digital immigrants part 1. On the horizon, 9(5), 1-6. 
https://doi.org/10.1108/10748120110424816

Sandars, J. (2005). Using web quests to enhance work based learning. Work Based Learning in Primary Care, 3, 210-217.

Segers, E., \& Verhoeven, L. (2009). Learning in a sheltered Internet environment: The use of WebQuests. Learning and Instruction, 19, 423-432. https://doi.org/10.1016/j.learninstruc.2009.02.017

Ulu, H., \& Ulusoy, M. (2018). A way in screen reading: improving the reading comprehension ability of fourth grade students through WebQuest-based teaching. Ana Dili Ë̆itimi Dergisi, 6(3), 591-635. https://doi.org/10.16916/aded.413690

Yoder, M. B. (1999). The student Webquest: A productive and thought provoking use of the Internet. Learning and Leading with Technology, 26(7), 6-9.

Zheng, R., Stucky, B., McAlack, M., Menchana, M., \& Stoddart, S. (2005). WebQuest learning as perceived by higher education learners. TechTrends, 49, 41-49. https://doi.org/10.1007/BF02824110

\section{Copyrights}

Copyright for this article is retained by the author(s), with first publication rights granted to the journal.

This is an open-access article distributed under the terms and conditions of the Creative Commons Attribution license which permits unrestricted use, distribution, and reproduction in any medium, provided the original work is properly cited. 